\title{
Verzeichnis der Formulierungsbeispiele
}

Alle Formulierungsbeispiele stehen unter ct.otto-schmidt.de zum Download zur Verfügung. Ihre persönlichen Zugangsdaten finden Sie eingedruckt gleich zu Beginn des Buches.

Rz. Seite

M 1 Beschränkung der Geschäftsführungsbefugnis . . . . . . . . . . $85 \quad 37$

M 2 Gesellschaftsrechtliche Sonderrechte . . . . . . . . . . . . . $104 \quad 45$

M 3 Gesellschafterrechte in der Einheitsgesellschaft . . . . . . . . . $150 \quad 65$

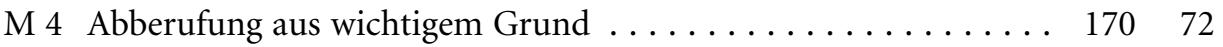

M 5 Forderungsverzicht mit Besserungsschein . . . . . . . . . . 594271

M 6 Rangrücktritt . . . . . . . . . . . . . . . . . . . . . . . . 595274

M 7 Verpfändungsvereinbarung..................... 714324

M 8 Geschäftsführerbestellung.................... 757338

M 9 Beschlussfassung Katalog zustimmungspflichtiger Geschäfte . . . $758 \quad 339$

M 10 Beschlussfassung Geschäftsordnung (einfache Version) . . . . . . 759341

M 11 Beschlussfassung Geschäftsordnung (ausführliche Version) . . . . 760342

M 12 Beschlussfassung Abberufung . . . . . . . . . . . . . . . 761346

M 13 Amtsniederlegung des Geschäftsführers in Gesellschafter-

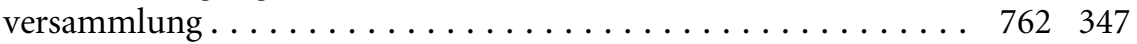

M 14 Anstellungsvertrag Fremd-Geschäftsführer . . . . . . . . . 763347

M 15 Anstellungsvertrag beherrschender Gesellschafter-Geschäftsführer 764355

M 16 Anstellungsvertrag Geschäftsführer GmbH \& Co. KG . . . . . . . 765361

M 17 Aufhebung Geschäftsführer-Vertrag . . . . . . . . . . . . . 766369

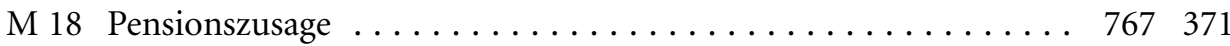

M 19 Tantiemevereinbarung ...................... 768373

M 20 Kündigungsschreiben Geschäftsführer-Anstellungsvertrag . . . . . 769375

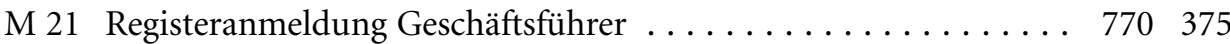

M 22 Ladungsschreiben Gesellschafterversammlung........... 771377 
